\title{
Improving product development: Towards a framework for integrating artefact and process models
}

\author{
M. Ranta ${ }^{1)}$, M. Mäntylä ${ }^{1)}$, R. Smeds ${ }^{2)}$, P. Haho ${ }^{2)}, J u k k a$ \\ Alvesalo ${ }^{2)}$ \\ ${ }^{1)}$ Department of Computer Science and Engineering \\ Helsinki University of Technology \\ P.O.B 5400, FIN-02015 HUT, Finland \\ Fax: $+358-9-4513293$ \\ Tel: +358-9-451 4807, e-mail: mervi.ranta@hut.fi \\ Tel: +358-9-451 3230,e-mail: martti.mantyla@hut.fi \\ ${ }^{2)}$ Enterprise Simulation Laboratory \\ Helsinki University of Technology \\ P.O.B 9555, FIN-02015 HUT, Finland \\ Fax: +358-9-4513665 \\ Tel: 358-9-451 3640,e-mail: riitta.smeds@hut.fi \\ Tel: 358-9-4515032,e-mail: paivi.haho@hut.fi \\ jukka.alvesalo@hut.fi
}

\begin{abstract}
This paper initiates a framework for improving product development processes. The starting point is the present gap between the theory of product and process models and their actual industrial application in practice. A case study of a multidisciplinary development process that has been processed in a simulation game is presented to concretize the needs for improvement. The case revealed that transparency of the product development process and artefact models is critical in coping with the key problems of conformance, rationale, dynamics, re-use, and milestone integration. Potential means of artefact modeling are discussed for each of the problems in order to propose directions for integrating artefact and process models.
\end{abstract}

Keywords

Product models, artefact models, product development, process model, process simulation, integration, transparency. 


\section{INTRODUCTION}

The product modeling applications and process simulation games constantly face problems in accurate and complete representation of reality. The difficulty seems to be that modeling of reality requires to at least some degree both the presentation of artefact and the presentation of the process. However, the combination of these two different viewpoints is not straightforward since their have been created and developed separately with very different objectives. The current approaches and systems for each of these two models are discussed in the following to give a basis for discussing the possibilities for their integration.

Product models have developed from detailed descriptions of the physical form towards a total model that is applicable through the whole product life cycle (e.g. Ranta and Mäntylä 1997). Product models are turning from central and homogeneous databases towards means to manage the distributed and specific product presentations of the computer systems and partners along the engineering processes. These include bills-of-material to represent the component structure, features to integrate shape and manufacturing information, modules for supporting configuration management, and interdependent models for such disciplines as electronic, mechanical, and software designs. Solutions for allowing the heterogeneity and distribution are searched from ontology approaches (e.g. Mäntylä and Ranta 1998, Ranta et al. 1999, Büchner et al. 1999).

Another product modeling trend is the capturing of deeper information and efforts to keep track on all the background information that is created and used during the engineering processes (e.g. Lahti et al. 1997). The motivation lies in the requirements for better knowledge management and further in the development effort towards a learning organization that concerns the enterprises as whole. In case of product development it is necessary to capture all the background information that the product developers apply and to represent the rationale that lead to the design decisions.

Thus, there is a shift from conventional product models towards richer artefact models that present all the requirements, documents, issues and rationales along the development process. An artefact model puts emphasis on the customer requirements, the target services, and on capturing the development steps that lead to the final product definition. The aim is to make the product and related process knowledge explicit and transparent, so as to be able to use and reuse this knowledge in later phases of a design process and in further development projects.

In the practical modeling and design of $R \& D$ processes, a process model usually is a flow chart, which shows the process tasks, the connecting information and material flows, and the milestones. It presents explicitly the product development process as it is planned to be carried out in a company. The difficulty lies in tracing the processes and obtaining a coherent view on them, since the processes cut through many departments and units, and people from these different organizations often have quite different views on how things really happen.

Simulation games solve this problem by collecting all the related people together around the visualized process model, for a systematic walk through and "talk 
through" of the process (e.g. Smeds, 1994, 1997, Smeds and Haho, 1995, Haho 1998). The simulation games reveal that the process models act as presentations of the ideal situation, i.e., the way that people wish things should be or the way they would like to change things to be. Partly this results from the necessary level of abstraction that leaves details open and partly from the fact that people execute processes in more or less unpredictable way, using a lot of experience, tacit knowledge and human communication that is not included in the idealized process model. The gap between the models in theory and the models in practice is obvious.

However, this gap can be utilized as a trigger for process improvement. One important use of process models is to create new improved ways to carry out the processes and introduce them to the involved parties. The improvements can be discovered by analyzing and simulating the existing processes and taking into account the changes in the environment and the strategic development objectives of the company.

The following section describes the development process of an example product and the process simulation game that was carried on it. The third section concludes the problems that the case study revealed in the quality of the process models. The fourth section proposes potential artefact modeling approaches for overcoming the problems. Finally the last section presents conclusions and future research plans.

\section{PRODUCT DEVELOPMENT CASE STUDY}

The case enterprise offers complex high-technology systems on business-tobusiness markets. Its organization consists of competence based organizational units and product development teams that are guided by competence specific processes. The product portfolio consists of a variety of different electronics ranging from independent hand-held pieces of equipment to complex and modular, interconnectable systems. The most compelling challenge imposed on the R\&D department by the market is the combination of rapidly developing technologies and the ever-shortening product development times. The main means of reaching the goal, has so far been process development by integrating the functional subprocesses into a more manageable and structured process system.

A simulation game was set up for a walk through of the process stages that had taken place during the development process of a complex multidisciplinary product. The game was based on a process chart that covered the whole process from front-end-study until reaching general availability and consisted of four parallel disintegrated sub-processes. However, here the attention is focused on the co-design of hardware and software in order to keep the example comprehensive.

\subsection{Co-design process}

The decision to start the development project was quite intuitive and the estimate of the required development effort for the embedded software was severely 
underestimated, causing the project to initially place almost equal attention on both hardware and software development.

Typically hardware development proceeded through iterations of prototype development and testing. Each test reveals modification needs that are input for the specifications of the next prototype. The dependency between hardware and software forces the software development to continuously adjust to the changes taking place at the hardware side.

The rapidly changing technologies further increased the amount of changes. The project was run as a derivative product development project, but the amount of required new technology development revealed to be huge and attempts to follow the fixed schedule failed. As the introduction of new technologies caused a lot of work from earlier stages to become obsolete the schedules were slid in a manner that became less and less manageable with time.

As time passed, the project lost its direction and several unsuccessful attempts were made in order to get it back on its track. The massive amount of software development required for completing the project was noticed and more and more new personnel were added to the project. Eventually the project came to a point where nobody any longer had a clear picture of the whole.

\subsection{Simulation game discoveries}

The functional sub-processes of the company were disintegrated without clear program management for binding them together. Common milestones with moderator-lead formal reviews were introduced to improve the integration. However, the simulation game showed that the contents of the milestones and their exit criteria were fuzzy. For example, while the required documents might exist, their contents could be inadequate.

It was very obvious that different people had different views to the process; as well on how things actually happened and as on how they should ideally happen. Here lies the strength of carrying a simulation game that gathers all related people to one place for going through each step and agreeing on a common understanding. Still, the process model remains easily vague: is not clear whether it documents an old process, current or future practice, and what is the proper level of details and accuracy. Moreover there remains a difference between the ideal process chart and the actions that people actually carry out to keep things going.

The enterprise has previously enjoyed a natural organizational closeness and a good level of interpersonal contact. Now the rapid growth of the enterprise is causing new problems to the communication during the product development process. The fact that teams are no longer co-located in the same physical space has created a need for intensive use of modern communication systems and documentation, not always achieving the same level of efficiency as personal contact would. 


\section{PROBLEMS}

The following problems of process model quality can be concluded from the presented case study.

\section{Conformance}

The process models present an ideal picture of the stages of the development process. However, the conformance to what takes place in practice is not ensured. For example, some loops and dependencies may have been omitted, and in particular in case of urgent difficulties and errors people take actions that are not drawn to the process charts. A process model appears quite different depending whether one day, one week, or one month was spent on drawing it.

\section{Rationale}

Process model is commonly used as a tool for a group of people to discover their common understanding of what happens during a process. The starting point is to accept certain idealization, since the group members have an agreed way of reading the model according to background information. However, the process model is presented just as the resulting chart without the rationale that lies behind it. Thus, an outsider has no guidelines for interpretation and may read the model in many ways.

\section{Dynamics}

Product development includes a lot of change propagation and iteration, which makes it a very dynamic process. Thus, it would be crucial that process models would be capable of reflecting such situations and supporting simulation of the various possibilities. The ability to present dynamics is limited without artefact models that are the triggers for the alternative paths.

\section{Reuse}

Process model presentations appear very solitary although existing designs, models and experience should be applied as much as possible. Things are not developed each time all over from beginning, and this should be shown clearly in the process model. The aim is to establish a framework that can then be used for creating the instances that match the requirements of a new product.

\section{Milestone integration}

The sub-processes, such as parallel hardware and software development in the example, are synchronized and integrated at milestones. A review is held in order to make the go/no-go decision according to exit criteria. Appropriate artefact presentation is necessary for stating and evaluating the exit criteria on the required documents, document contents etc. 


\section{MEANS OF ARTEFACT MODELLING}

We propose that better articulation of the artefact models is a key for solving the above stated problems. Visualizing the artefact model in connection with the process model and integration of these two models leads to improved product development.

\section{Conformance}

Process models usually present a generic model of the development process, although they are applied for example in simulation games in connection of particular development cases. A possibility for improving the conformance is to replace the ideal model with a much more concrete model of the specific case and using "real" sample artefacts and their related documentation in the model.

\section{Dynamics}

Presentation of the dynamic nature of processes requires the inclusion of the information that triggers the changes and is the target of the change management. Thus, artefact models should be included and represented as structural models to allow expressing dependencies and addressing the change propagation properly. Product data management offers facilities such as versioning and module management upon which to build structured artefact models.

\section{Reuse}

Product development is usually based on the usage of previous experience, which is often captured in artefact models of previously developed products. Better reuse can be achieved by abstract definitions of product architectures that support configuration of a wide variety of artefacts according to changing requirements. A further improvement is possible if the artefact model includes its design rationale, i.e., the design decisions and background information that led to the final product. Thus, a design process model is attached to the artefact model to facilitate the carrying of the rationale.

\section{Milestone integration}

The integration and decision making at milestones becomes easier if the development process is as transparent as possible. Transparent access to artefact related documentation is needed to evaluate the exit criteria not only according to the existence of documents but also their contents. Inclusion of rationale information in artefact models provides information on the quality of the process that lead to the current artefact model, for example it is possible to check that sufficient number of alternative solutions were considered and to view the criteria for choosing among the alternatives. 


\section{CONCLUSIONS}

This paper proposes that better integration of process and product models would result in major improvement in product development. According to the presented case study and practical experience from similar industrial process model applications five key problems can be listed: conformance, rationale, dynamics, reuse, and milestone integration. All of these problems indicate that more refined process models are needed and artefact models should be articulated properly to provide more concrete support for the process models.

The problems and presented potential means to cope with them are all related to making the product development more transparent. First of all it is necessary to capture what is happening during the different development stages and make it visible. In addition to this the captured information and models must be made transparent to all parties so that it is possible to constantly follow and afterwards trace the rationales and dynamics behind decisions and end results.

This paper initiates a joint research of the Enterprise Simulation Laboratory (http://simlab.hut.fi) and the Product Modeling and Realization Group (http://www.cs.hut.fi/ mra/PM\&RG.html) that aims to develop a framework for combining the process and artefact modeling facilities to allow improved product development. The next steps will include:

- Determining the artefact structures and documentation for the example product.

- Defining how the collected artefact model presentations can be attached to the product development process and visualized during a simulation game.

- Carrying out a simulation game that is enriched with the artefact model and analyzing the affect on conformance, rationale, dynamics, re-use, and milestone integration as well as detecting further needs for improvement.

\section{REFERENCES}

Büchner, A., Ranta, M., Hughes, J., and Mäntylä, M., (1999) Semantic Information Mediation among Multiple Product Ontologies Proc. 4th World Conference on Integrated Design \& Process Technology, 1999.

Haho, P. (1998) Tailored simulation games for successful business process development. In: R. Smeds \& J. O. Riis (Eds.) Experimental Learning in Production Management. Chapman \& Hall, UK, 1998, 24-39.

Lahti, A., Mäntylä, M., and Ranta M. (1997) Capturing and deploying design decisions. In M. Pratt, R.D. Sriram and M.J. Wozny (editors), Proc. IFIP WG 5.2 Geometric Modelling Workshop, May 1996, Airlie, Virginia. IFIP Proceedings, Chapman \& Hall, London, 1997.

Mäntylä, M., and Ranta, M. (1998) Engineering Process Ontologies for Communication, Co-operation, and Co-ordination in a Virtual Enterprise, CDRom of Prolamat '98, Trento, Italy, September 1998. 
Ranta, M., Büchner, A., Mäntylä, M., and Hughes, J. (1999) Collaboration in Heterogeneous Environments along Product Processes, Proc. 4th World Conference on Integrated Design \& Process Technology, 1999.

Ranta, M. and Mäntylä, M. (1997) Re-use of product model through life-cycle stages. 3rd WDK Workshop on Product Structuring, June 26-27, 1997, Delft University of Technology, The Netherlands.

Smeds, R. (1994) : 'Managing Change towards Lean Enterprises'. International Journal of Operations \& Production Management, 1994, 14/3, 66-82.

Smeds, R. (1997): Organizational learning and innovation through tailored simulation games: Two process re-engineering case studies. Knowledge and Process Management. The Journal of Corporate Transformation, Vol 4, No 1, 22-23.

Smeds, R. and Haho, P. (1995) Tailored order-to-delivery process game, in Simulation Games and Learning in Production Management (ed. J. Riis), Chapman \&Hall, London, 145-155.

http://simlab.hut.fi (17-Dec-1998 13:03:19 EET) The homepage of the SimLab project.

http://www.cs.hut.fi/ mra/PM\&RG.html (5.5.1999, Mervi.Ranta) The homepage of the Product Modeling\&Realization Group, PM\&RG.

\section{BIOGRAPHY}

Mervi Ranta is a research scientist of the Product Modeling and Realization Group (PM\&RG) at Department of Computer Science and Engineering in the Helsinki University of Technology. She received her M.Sc. in Computer Science from Helsinki University of Technology in 1987. During 1988-1992 she was a visiting researcher at the Kimura Laboratory in the Department of Precision Machinery Engineering of the University of Tokyo. Her research interests include artefact modelling, artefact model reuse and life-cycle, distributed product processes, virtual engineering, and product concept generation.

Martti Mäntylä received his Dr.Eng. in 1983 at the Helsinki University of Technology. In 1983-1984 he was a visiting scholar with the Computer Systems Laboratory at the Stanford University, 1989 a World Trade Visiting Scientist at the IBM Thomas J. Watson Research Center in Yorktown Heights, NY,1996-1997 a visiting scientist at the Fraunhofer Institute for Computer Graphics in Darmstadt, Germany. Currently he is Professor of Information Technology and heads the Laboratory of Information Processing Science at the Helsinki University of Technology, Finland. Dr. Mäntylä's research interests include the full range of computer applications in engineering.

Riitta Smeds is lecturer and head of the Enterprise Simulation Laboratory at Helsinki University of Technology, Department of Industrial Engineering and Management, and Docent at the Swedish School of Economics and Business Administration, Department of Management and Organization. She holds a M.Sc. (Tech.), a Lic.Sc. (Tech.), and a D.Sc. (Tech.) in Industrial Management from 
Helsinki University of Technology. Her main research areas are enterprise evolution, management of technology and innovation, organizational learning and change, business process re-engineering, and enterprise simulation methods.

Päivi Haho, MSc (Eng.) is a researcher of the Enterprise Simulation Laboratory at Helsinki University of Technology, Department of Industrial Engineering and Management. Earlier she has been responsible for the management of change projects in international business process reengineering projects in industry. She has developed simulation games (since 1988) and business process development methods in her jobs. Her current research interests include participative management of change in enterprise transformation and dynamics of knowledge creation and accumulation in industrial organizations.

Jukka Alvesalo is a student in a Master's level program at the Department of Industrial Engineering and Management at Helsinki University of Technology, and as well in a Master's level program at the Department of Management and Organization at the Swedish School of Economics and Business Administration. His research interests include the fields of high-technology product development and management in high-technology companies. 